\title{
The remarkable effects of an electrodeposited copper skin on the strength, and the electrical and thermal conductivities of reduced graphene oxide printed scaffolds
}

Juan José Moyano ${ }^{1}$, Iñaki Garcia², Juan de Damborenea², Domingo Pérez-Coll ${ }^{1}$, Manuel Belmonte $^{1}$, Pilar Miranzo ${ }^{1}$, Maria Isabel Osendi ${ }^{*}$

${ }^{1}$ Instituto de Cerámica y Vidrio, CSIC, Campus de Cantoblanco, 28049 Madrid, Spain

${ }^{2}$ Centro Nacional de Investigaciones Metalúrgicas CENIM-CSIC, av. Gregorio del Amo 8, 28040 Madrid, Spain

\section{Keywords}

3D printing, electroplating, graphene oxide (GO), copper, $\mathrm{Cu}$ mesh, thermal interface material (TIM), heat dissipation,

\begin{abstract}
Architected $\mathrm{Cu} / \mathrm{rGO}$ (reduced graphene oxide) heterostructures are achieved by electrodepositing copper on filament printed rGO scaffolds. The Cu coating perfectly contours the printed $\mathrm{rGO}$ structure, but isolated $\mathrm{Cu}$ particles also permeate inside the filaments. Although the $\mathrm{Cu}$ deposition conveys certain mass augment, the 3D structures remain reasonably light (bulk density $\cong 0.42 \mathrm{~g} \mathrm{~cm}^{-3}$ ). The electrical conductivity $\left(\sigma_{e}\right)$ of the $\mathrm{Cu} / \mathrm{rGO}$ structure $\left(\sim 8 \times 10^{4} \mathrm{~S} \cdot \mathrm{m}^{-1}\right)$ shows a notable increment compared to $\sigma_{e}$ of the rGO structure $\left(\sim 4 \times 10^{2} \mathrm{~S} \cdot \mathrm{m}^{-1}\right)$. The effect on the scaffold robustness is also notable with an increase of the compressive strength by nearly ten times (from $20 \mathrm{kPa}$ of the rGO scaffold to $150 \mathrm{kPa}$ of the $\mathrm{Cu} / \mathrm{rGO}$ structure) and cyclability as well. The improved thermal conductivity of the $\mathrm{Cu}$ coated scaffolds ( $\sim 4$ times higher), in addition the $\sigma_{\mathrm{e}}$ and strength improvements, suggests that $3 \mathrm{D} \mathrm{Cu} / \mathrm{rGO}$ structures could be suitable assemblies for integration into thermal dissipation systems, particularly as thermal interface materials, for compact electronic devices.
\end{abstract}




\section{Introduction}

Copper/graphene composites and heterostructures result appealing materials for a variety of applications; which include their utilization for the energy production and storage, typically as electrodes in supercapacitors and Li-ion batteries, ${ }^{1-3}$ but also as back electrodes in halide perovskite solar cells where a $\mathrm{Cu}$-based interface favors transport from the perovskite side to the carbon electrode. ${ }^{4,5}$ Equally interesting are their uses as highly selective electro-catalytic bio-sensors for detecting of dopamine neurotransmitter and essential human aminoacids ${ }^{6,7}$ or as electro and photo-catalysts for the transformation of $\mathrm{CO}_{2}$ into hydrocarbons. ${ }^{8,9}$ In the latter case, the coupling of the photocatalytic element to a photovoltaic cell produced a particularly efficient and inexpensive set. ${ }^{10}$ Applications for thermal management issues deserve special mention, for example as thermal interface materials (TIM), heat sinks and heat spreaders, intended for a rapid dissipation of the heat produced in highly-packed integrated circuits, ${ }^{11-13}$ and also, as heat transfer coatings for effective heat dissipation in industrial boilers via phase change heat transfer. ${ }^{14}$

For many of the above applications, the interfacial characteristics between copper and graphene along with the particular microstructural arrangement, e.g. porosity at different scales and nanostructuring, seem essentials for charge and phonon transfers and hence to enhance performance..$^{4-5,8-9}$

Improvements of mechanical, electrical and thermal properties have been proved in bulk $\mathrm{Cu} /$ graphene composites,${ }^{15}$ especially for processing conditions that prompted extreme alignment of the graphene nanostructures, which accordingly produced anisotropic composites. ${ }^{16}$ In the case of composite foils and heterostructures of $\mathrm{Cu} / \mathrm{graphene}$ and $\mathrm{Cu} /$ reduced graphene oxide (rGO), the usual fabrication routes include electrodeposition ${ }^{1}$ and chemical vapor deposition $(\mathrm{CVD})^{17}$ of graphene on $\mathrm{Cu}$ 
substrates, but co-electrodeposition of both $\mathrm{Cu}$ and graphene to attain composite foils has also been reported. ${ }^{18,19}$ Other fabrication methods include the selective laser patterning of graphene wrapped $\mathrm{Cu}$ nanoparticles,${ }^{20}$ the simple slurry coating of copper foils with a mix of reduced $\mathrm{GO} /$ hexagonal $\mathrm{BN}^{21}$ and the spin coating of a copper foil with a silk fibroin solution as the $\mathrm{N}$ - doped graphene precursor, followed by treatment in a microwave plasma reactor. ${ }^{22}$

However, examples of the opposite process, i.e. depositing/growing $\mathrm{Cu}$ over graphene are rather rare and normally preformed on flat electrodes. Examples include $\mathrm{Cu}$ electroplating directly on flat rGO electrodes ${ }^{23}$ using copper sulfate solutions, $\mathrm{Cu}$ electrodeposition on a graphene film over $\mathrm{SiO}_{2} / \mathrm{Si}$ substrate for interconnects in integrated circuits ${ }^{24}$ or via an intermediate $\mathrm{Cu}-\mathrm{Pt}$ buffer layer, dip-coated in a GO slurry. ${ }^{25}$

Results for $\mathrm{Cu} / \mathrm{graphene-based} \mathrm{porous} \mathrm{composites} \mathrm{are} \mathrm{exceptions} \mathrm{and} \mathrm{deserve} \mathrm{particular}$ mention. For example, $\mathrm{Zhao}$ et $\mathrm{al}^{2}{ }^{2}$ prepared a $\mathrm{Cu}-\mathrm{CuO} \times \mathrm{rGO}$ aerogel through the catalytic reaction between both $\mathrm{GO}$ and a $\mathrm{Cu}$ reagent solutions, reporting its supercapacitor performance. Rho et al. ${ }^{12}$ partially sintered $\mathrm{Cu}$ micro-particles into a porous form (35\% porosity) and coated it with CVD graphene, which produced an enhancement of the thermal conductivity. Mirzaee et al. ${ }^{1}$ electrodeposited GO nanosheets over a $\mathrm{Cu}-\mathrm{Ni}$ foam that, after $\mathrm{GO}$ reduction, performed as high energy-high power density supercapacitor. Perreault et al. ${ }^{3}$ prepared a mesoporous nanocomposite of graphene wrapped Ni-Cu oxide microspheres by the spray drying method. Finally, Lamberti et al. ${ }^{26}$ described the hydrothermal deposition and reduction of a GO layer around $\mathrm{Cu}$ wires, which they used as knitted wire for wearable cloth devices, whereas Pedico et al. ${ }^{27}$ tested carbon fibers with an active coating of copper sulfide decorated GO aerogel for the fabrication of a fiber-shaped flexible supercapacitor. 
Compared to the above methods, the additive manufacturing of porous $\mathrm{Cu} / \mathrm{rGO}$ composites and heterostructures presents a number of advantages, such as a full control over the assembly and shape, and the possibility of imposing hierarchical porosity and directionality features with their clear effect on properties. ${ }^{15-16}$ Besides, model predictions for the mechanical properties of 3D graphene structures based on the assembly architecture have been implemented ${ }^{28}$ which offers a powerful control tool. Previous works on the $\mathrm{Cu}$ additive manufacturing include the dual direct ink writing (DIW) of $\mathrm{Cu}$ and GO into an interdigitated supercapacitor, where the copper layer acted as current collector, ${ }^{29}$ and the printing of hierarchical nanoporous pure copper scaffolds via DIW and later de-alloying. ${ }^{30}$ Conversely, the 3D printing of graphene based scaffolds has been fully reported using GO inks, ${ }^{31-33}$ pristine graphene nanoplatelets ${ }^{34}$ and even mixtures of both. ${ }^{35}$

Furthermore, $\mathrm{Cu}$ electroplating is in principle a relatively facile and scalable method of building $\mathrm{Cu}$ coatings either on solid carbon substrates ${ }^{36-37}$ or on porous carbon nanotubes (CNT) mats, ${ }^{38-40}$ where full $\mathrm{Cu}$ infiltration inside the mats resulted problematic. Accordingly, complex routes have been tried to fill pores with copper, such as first electroplating in an organic solution for nucleation of $\mathrm{Cu}$ particles over the nanotubes, followed by electrodeposition in an aqueous solution to fill the pores. ${ }^{38}$ At this point, it is valuable to consider the technology developed for the volume fabrication of 3D stacked integrated circuits, ${ }^{41-42}$ for which copper plating must provide a void-free filler for through-silicon-vias at short electroplating times. Satisfactory filling depends on factors such as substrate dimensions, current density, current waveform, copper bath composition, mass transport phenomena and seeding. Electrolytes with three additives accelerator, leveler and suppressor have traditionally been used. ${ }^{41}$ The accelerator is a surfactant molecule that increases the deposition rate as 
a function of surface coverage. The suppressor is a large chain polymer that inhibits deposition. The leveler behaves like a grain refiner and helps reducing overburden thickness. Finally, chloride is the common fourth chemical species in copper plating, competing with suppressor-accelerator ones on the cathode surface, and necessary for suppressor effectiveness.

We have explored an approach for developing metal-coated porous rGO scaffolds in a technologically simple and scalable way by profiting of the experience in $\mathrm{Cu}$ electroplating for the industrial fabrication of stacked integrated circuits. The present work represents the first attempt to strengthen the 3D rGO structure and achieving also high electrical conductivity and improved heat conduction through $\mathrm{Cu}$ electroplating. Recently, the need of multifunctional materials based on graphene films, having high thermal conduction and compressibility to be used as TIM and thermally conductive gap filling materials in flexible electronics, artificial intelligence and high-power, highfrequency electronics has been signaled. ${ }^{12-13,43-45}$ The development of multifunctional thermal management materials based on graphene, capable of acting as film heaters for future electronic devices in aircrafts and computers has also been recently stressed. ${ }^{43}$ Equally, methods offering the possibility of microstructural modulation in lowdimensional materials instead of random orientation are considered of maximum interest for control of heat flow in TIM $;^{44}$ along this line, novel TIM foams based on 2D materials, such as graphene or BN, outperformed current TIM in all aspects. ${ }^{45,46}$ In addition to the above, the need for new conductive composites as substitutes for the heavy metallic meshes, such as the copper mesh, which are capable of tackling problems such as lightning striking and ice accumulation in aircrafts, has been recently reviewed owing to its engineering impact. ${ }^{47}$ Different solutions including acting over 
the mesh geometry and decreasing its thickness, the use of a network of metal coated carbon fiber and conductive graphene paper have been proposed. ${ }^{47-48}$ In consequence, the concept of using graphene-type porous architected materials as manageable and lightweight supports for metal electroplating developed in the present work seems a promising, cost-effective and scalable approach to address some of the addressed challenges.

\section{Experimental Section}

The 3D GO structures were assembled by filament printing using an ink prepared from GO powders (N002-PED, Angstron Materials Inc., USA), with nominal thickness of 2-3 $\mathrm{nm}$ and in-plane length $\leq 7 \mu \mathrm{m}$. The ink preparation method has been described in a previous paper; ${ }^{49}$ in brief, GO powders were added to an aqueous solution containing two cationic surfactants, namely two polyethylenimines of different molecular weight (H-PEI, $\mathrm{Mw}=25000 \mathrm{~g} \mathrm{~mol}^{-1}$; L-PEI, Mw $=2000 \mathrm{~g} \mathrm{~mol}^{-1}$, the last in a $50 \mathrm{wt} . \%$ aqueous concentration; Aldrich Chemical Co., USA). Next, polyethylene glycol (PEG, Mw $=8000$ $\mathrm{g} \mathrm{mol}^{-1}, 60$ wt.\% concentration, Fisher Scientific, USA) was added to adjust the ink viscosity. The mixture was stirred in a high shear mixer (AR-250; Thinky Company, USA) to get the required homogeneity. The resulting ink contained 4.8 GO, 7.1 H-PEI, 1.3 L-PEI, 3.6 PEG and 83.2 of added water (all in wt.\%). This ink had a convenient viscoelastic behavior and values of the elastic storage modulus $\left(8.5 \times 10^{4} \mathrm{~Pa}\right)$ and yield stress $(\sim 900 \mathrm{~Pa})$ under cycling shearing conditions that granted printability. ${ }^{49}$ Woodpile type GO structures of sixteen layers were computer designed (RoboCAD 4.2, 3-D Inks LLC, USA) and printed using a three-axis robocasting system (A3200, 3-D Inks LLC, USA) at room temperature onto flat alumina substrates. A nozzle of $410 \mu \mathrm{m}$ diameter (Precision Tips; EFD Inc., USA) was used for extruding the filaments, using a distance 
between in-plane adjacent filaments $(a)$ of $1100 \mu \mathrm{m}$ and a printing speed of $10 \mathrm{~mm} \cdot \mathrm{s}^{-1}$. The as-printed scaffolds were immediately frozen by immersion in liquid nitrogen at 77 $\mathrm{K}$ for $\sim 10 \mathrm{~s}$ and subsequently freeze-dried (Freezone Plus 12L, Labconco Corp., USA) for assuring their mechanical integrity. ${ }^{49}$ The dimensions of the as-printed lattices were $12.5 \times 12.5 \times 5.0$ (all in $\mathrm{mm})$.

Scaffolds were treated at $1200{ }^{\circ} \mathrm{C}$ in a graphite furnace (Astro model 1000-3560-FP20, Thermal Technology Inc., USA) under nitrogen atmosphere (0.11 MPa) to remove most of the oxygenated groups in GO and burn out the organic compounds in the ink. ${ }^{48}$ Bulk density of the different scaffolds was estimated by weighing and measuring the structures. After the thermal treatment, the scaffold presented an assembly of filaments of $\sim 400 \mu \mathrm{m}$ diameter, distanced $\sim 1070 \mu \mathrm{m}$ (in-plane) and $\sim 620 \mu \mathrm{m}$ between equivalent (out-of-plane) layers.

For electrodeposition experiments, the rGO scaffold was glued with graphite paste onto a copper strip and placed at the center of the plating bath facing a platinum anode at a distance of $1 \mathrm{~cm}$ and using a $\mathrm{Ag} / \mathrm{AgCl}(3 \mathrm{M} \mathrm{KCl})$ reference electrode. The metal strip was previously covered with lacquer to prevent contact with the electrolytic bath $(50 \mathrm{ml}$ of volume). The electrodeposition was carried out at room temperature without agitation, applying a constant voltage of $-150 \mathrm{mV}$ to the scaffold vs. the reference for 60 $\min$.

The composition of the aqueous electrolyte bath used in all plating tests was $225 \mathrm{~g} \cdot \mathrm{L}^{-1}$ $\mathrm{H}_{2} \mathrm{SO}_{4}$ (98\%, Puriss., Panreac, Spain), $60 \mathrm{~g} \cdot \mathrm{L}^{-1} \mathrm{CuSO}_{4}$ (anhidro, Prs-Codex, Panreac, Spain) with the following minor additives: 290 ppm of polyethylene glycol (PEG3350 BioUltra, Sigma Aldrich, USA), 60 ppm of $\mathrm{Cl}^{-}$(from $\mathrm{HCl}, 37 \%$, Technical grade, Panreac, Spain) and 22 ppm of bis-sodium sulfopropyl-disulfide (HPLC, Chem-Impex International, USA) in millipore water (resistivity $>10 \mathrm{M} \Omega \cdot \mathrm{cm}$ ). 
The $\mathrm{Cu}$ deposited specimens were characterized by X-ray diffraction (XRD) methods (Vantec D8 Advance, Bruker, USA) with a $\mathrm{Cu}-\mathrm{K} \alpha$ monochromatic radiation source $(\lambda=$ $1.541 \AA$ Å). Confocal Raman spectroscopy (Alpha 300, Witec, Germany) was used to record Raman spectral images on polished sections of the $\mathrm{Cu} / \mathrm{rGO}$ scaffolds (embedded in epoxy resin). A laser wavelength excitation of $532 \mathrm{~nm}$ was employed. A representative region of a filament cross section of $10 \times 10 \mu \mathrm{m}^{2}$ close to the filament surface was scanned, recording 1 spectrum per pixel. Tomographic images of the $\mathrm{Cu} / \mathrm{rGO}$ specimens were obtained with a CT-Scan (XT H-160, Nikon, Tokyo, Japan). The microstructure of the $\mathrm{Cu} / \mathrm{rGO}$ specimens was analyzed with a field emission scanning electron microscope (SEM, Hitachi S-4700; Hitachi, Japan) on the specimen surface and on polished cross section as well. Elemental $\mathrm{Cu}$ line profiles were carried out on polished filament crosssections by energy dispersive X-ray spectroscopy (EDS).

Bare and $\mathrm{Cu}$ coated scaffolds were tested under uniaxial compression using a single column electro-mechanical testing machine (ZwickiLine Z5.0TS, Zwick-Roell, Germany) at a constant displacement rate of $0.5 \mathrm{~mm} \cdot \mathrm{min}^{-1}$ until the sample failure. Lattices of dimensions $11.6 \times 11.6 \times 4.5$ (in mm) were tested facing the square side, using at least 3 specimens per condition. Stress was calculated dividing the applied load by the sample loading surface area. The corresponding compressive strengths were estimated from the maximum stress before the sample collapse ( $\mathrm{rGO}$ ) or from the stress reached at the onset of the plateau region in the stress-strain plots $(\mathrm{Cu} / \mathrm{rGO})$.

The electrical conductivity measurements were done in the whole structures by a direct current 4 probe setup following the same methodology earlier reported. ${ }^{49}$ Two opposite rectangular outer faces $(\sim 11.6 \times 4.5$, in $\mathrm{mm})$ of the scaffold were covered with silver conductive paste (Electrolube, ERSCP03B, UK), and dried at room temperature to provide equipotential conditions to the external surface. Another pair of parallel Ag 
electrodes was painted on two parallel inner filaments. Each electrode was connected to a silver spike painted over an alumina substrate (a scheme of the setting is shown in the Supporting Information, Fig. S1a). Voltage ( $\left.\mathrm{V}_{\mathrm{ap}}\right)$ was applied to the opposite outer lateral faces with a dc power supply (Agilent E3646A, USA) varying between 100 and $500 \mathrm{mV}$, whereas a multimeter (Keysight 34461A, USA) located in series was used for determining the current (I) flowing through the system. Another independent multimeter (Agilent 34401A, USA) was used for measuring voltage (V) between the inner electrodes. The electrical resistance $(\mathrm{R})$ on each structure was determined as the slope of the I-V linear plots. The apparent electrical conductivity was obtained from the relation $\sigma_{\text {app }}=$ $\mathrm{L} /(\mathrm{R} \cdot \mathrm{A})$, where L corresponds to the distance between the inner electrodes and $\mathrm{A}$ is the area of the external electrode surface.

Cooling rates of both scaffolds ( $\mathrm{rGO}$ and $\mathrm{Cu} / \mathrm{rGO}$ ) were recorded with an infrared camera (A325sc, FLIR Systems, Inc., USA) that was mounted on a tripod at a constant distance. To prevent the errors in the camera measurements due to the emissivity differences between the samples (bare and coated), the sample surface facing the IR camera was coated with a thin carbon film. Three different test conditions were used to compare quantitatively the different contributions to heat dissipation. For the type 1 test, both samples were heated at a temperature of $\sim 200{ }^{\circ} \mathrm{C}$ with a butane/air micro-torch during $\sim 15 \mathrm{~s}$, interposing a copper screen to avoid direct flame contact, two opposite sides of the scaffold frame were clamped by inserting mutual fiber mats (see scheme of the rig in Fig. S1b of Supporting Information). Each structure was cooled down in air and the temperature was recorded with the IR camera on the reticulated surface of the samples after removing the screen.

In type 2 tests, both structures were placed inside a purposely made insulating case with the intention of minimizing thermal convection in the heat flow; hence, for estimating 
the contribution of the conduction part solely in the heat dissipation. The encasing had a vertical slit of $1 \mathrm{~mm}$ opening (see scheme in Fig. S1c of Supporting Information) for the camera focusing. In this test, the scaffolds were placed sideways over a thick brass plate at room temperature $\left(\sim 23^{\circ} \mathrm{C}\right)$ whereas the opposite side was in contact with the hot side (at $\sim 60^{\circ} \mathrm{C}$ ) of a Peltier cell (Peltier Cell 618724, Amidata S.A.U., Spain) during 5 min. Then, the Peltier cell was removed and the temperature was continuously recorded in equivalent points of the specimen surface (in the middle of the insulting case gap) for each sample.

In the type 3 test, the encased samples were placed between the cold (at $\sim-5^{\circ} \mathrm{C}$ ) and hot faces (at $\sim 60^{\circ} \mathrm{C}$ ) of two Peltier cells to produce stationary unidirectional heat flow conditions, and the temperature profiles were recorded along each structure once thermal equilibrium ( $15 \mathrm{~min})$ was reached.

\section{Results and discussion}

The surface of the $\mathrm{Cu}$ electrodeposited scaffold changes its color from black to pale orange (Fig. 1a,b), but the cross section view reveals that the orange color is produced by a practically continuous skin enveloping the rGO structure (Fig. 1c). A SEM image of a single filament cross section confirms the occurrence of a $\sim 20 \mu \mathrm{m}$ thick $\mathrm{Cu}$ layer as shown by the overlaid elemental $\mathrm{Cu}$ line profile (Fig. 1d). The occurrence of some brilliant spots of variable size inside the filament, identified as $\mathrm{Cu}$ deposits (Fig. 1d), is confirmed as well.

Tomographic images of different sections of the $\mathrm{Cu} / \mathrm{rGO}$ sample also verify the existence of a continuous skin around the scaffold (Supporting Information, Fig. S2). Accordingly, full covering of the original rGO scaffold is achieved with the given electroplating conditions while reproducing the printed design. 
a)

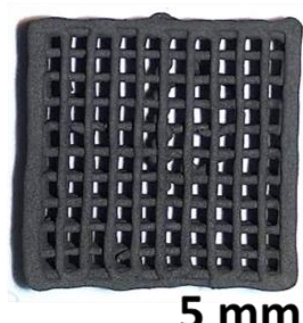

$5 \mathrm{~mm}$

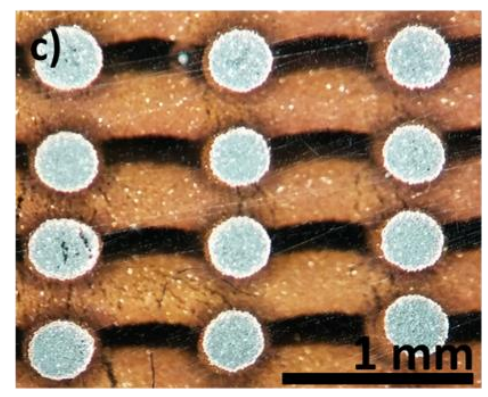

b)
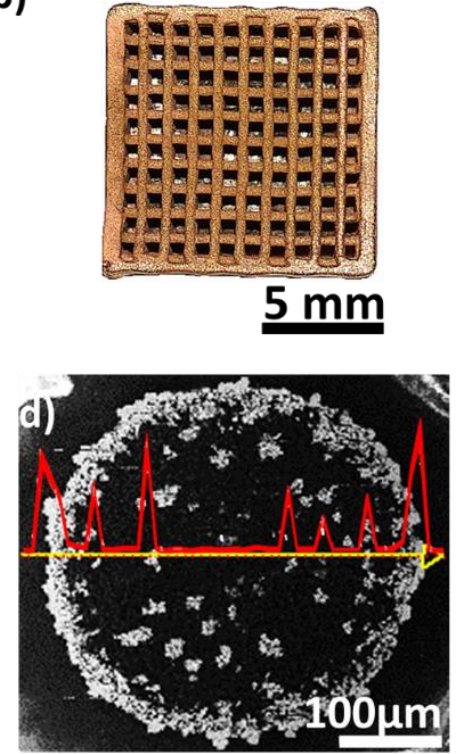

Figure 1. Optical microscope views of the bare rGO scaffold (a), the $\mathrm{Cu}$ electrodeposited sample (b), a polished cross section of the $\mathrm{Cu} / \mathrm{rGO}$ scaffold showing the contrast difference between the Cu coating and the rGO filament core (c) and SEM image of a single filament polished cross section with the overlaid EDS elemental $\mathrm{Cu}$ profile (red line) along the horizontal yellow axis depicted in the micrograph (d).

A closer SEM view of the rods in the scaffolds actually reveals different degrees of covering for the top and bottom layers (termed according to the distance to the counterelectrode of the electroplating bath). Certainly, a continuous and compact coating is distinguished on the surface of top-layer filaments (Fig. 2a,b), whereas a fragmented coating with rounded clusters of finer particles (Fig. 2c,d) is observed in filaments of bottom layers, and even GO sheets are distinguished underneath the rod surface (Fig. 2d). Consequently, although $\mathrm{Cu}$ penetrates the whole structure, the degree of covering diminishes towards the scaffold inner layers (further away from the Pt electrode).

Besides, SEM observations at higher magnification of a polished lengthwise cross section of a full coated filament (Fig. 3a) evidence the existence of a relatively compact 
coating, where the layer directly attached to the rGO filament is formed by agglomerates of smaller $\mathrm{Cu}$ grains (Fig. 3 b,c), whereas thicker compact grains grow in the outer rim (Fig. 3b). Cu deposits seem dispersed at random within the filament (Fig. 3a), and higher magnification images expose the rGO edges (marked by arrows in Fig. 3d,e), whereas the $\mathrm{Cu}$ aggregates appear filling the empty spaces among the rGO paths.
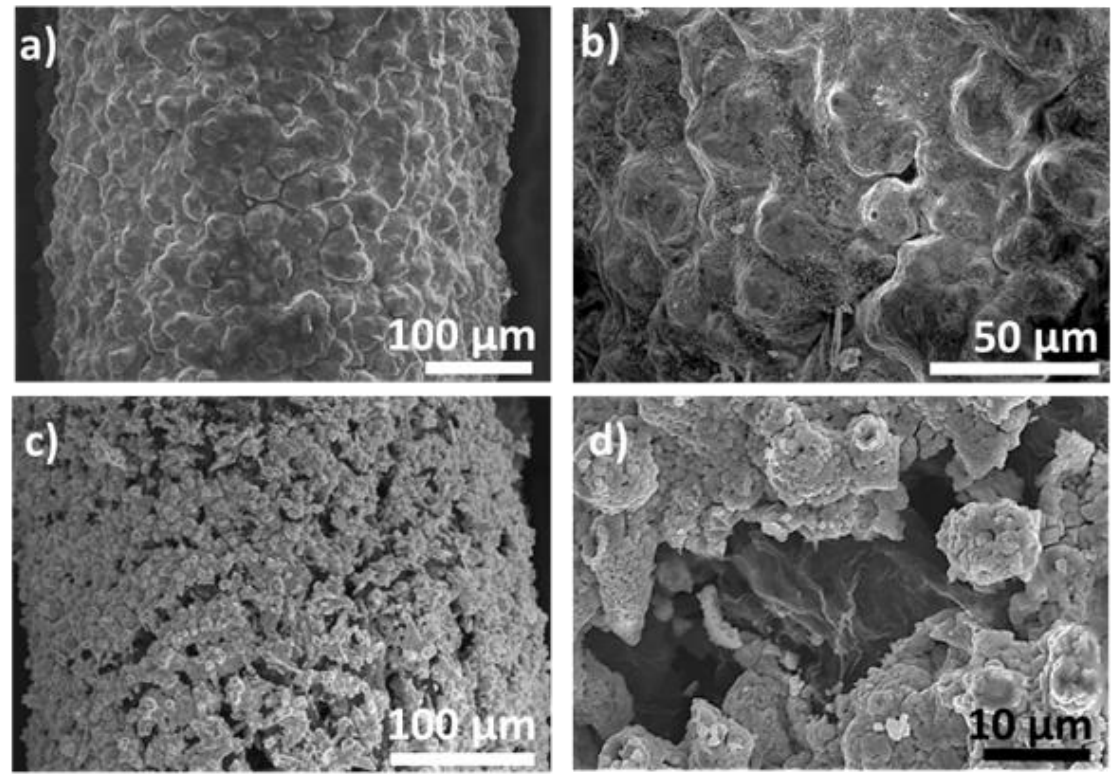

Figure 2. SEM views of coated rGO filaments of the structure top layer showing the full $\mathrm{Cu}$ covering (a), an enlarged a detail of the previous (b), analogous views for the bottom layer showing a fragmented $\mathrm{Cu}$ coating (c) and $\mathrm{rGO}$ sheets protruding beneath the $\mathrm{Cu}$ layer in the enlarged view of a bottom filament (d).

The XRD pattern of the $\mathrm{Cu} / \mathrm{rGO}$ scaffold (see Fig. S3 in Supporting Information) identifies both $\mathrm{Cu}$ and $\mathrm{Cu}_{2} \mathrm{O}$ phases. The occurrence of the latter is attributable to certain copper passivation in the air atmosphere, though the relative intensity of the maximum diffraction peaks in the pattern $\left(\mathrm{Cu} / \mathrm{Cu}_{2} \mathrm{O}=6.02\right)$ confirms elemental $\mathrm{Cu}$ as the major phase. 

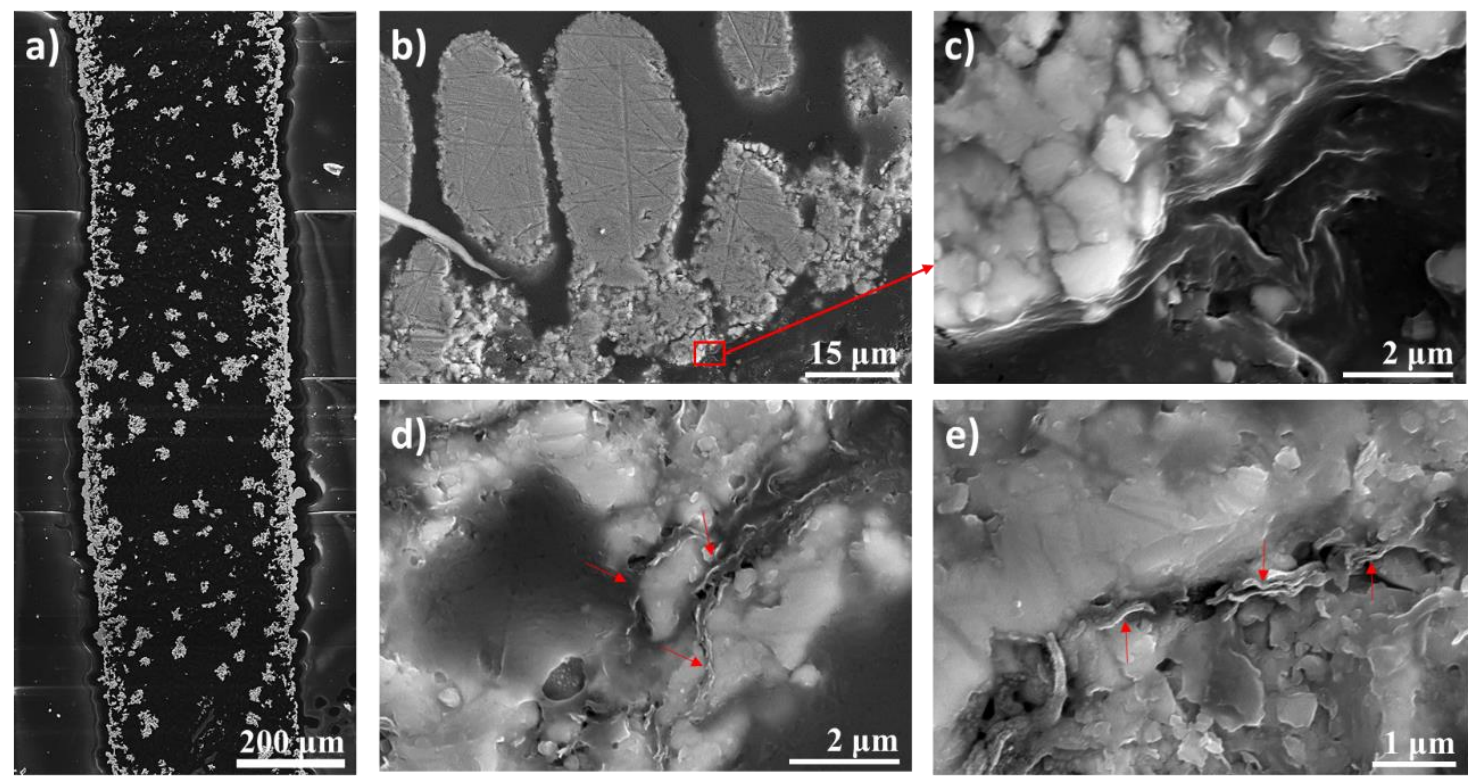

Figure 3. SEM views of a $\mathrm{Cu} / \mathrm{rGO}$ filament (polished lengthwise cross-section) showing the general perspective (a), a detail image of the $\mathrm{Cu}$ coating (b), an enlarged view of the interfacial region between the $\mathrm{Cu}$ coating and $\mathrm{GO}$ network (c), and $\mathrm{Cu}$ particles agglomerates (white color) filling the space between rGO flakes (red arrows) at two magnifications (d,e). Grey smooth zones correspond to the embedding resin.

Micro-Raman spectroscopy allows a better appraisal of the phases involved in the $\mathrm{Cu} / \mathrm{rGO}$ structure. A lengthwise filament section is shown Fig. 4a, enclosing the region (red square near the filament surface) used for the Raman scans. The average spectrum of this region (Fig. 4b) shows the common D $\left(\sim 1320 \mathrm{~cm}^{-1}\right), \mathrm{G}\left(\sim 1560 \mathrm{~cm}^{-1}\right)$ and $2 \mathrm{D}$ $\left(\sim 2700 \mathrm{~cm}^{-1}\right)$ graphitic bands ${ }^{50}$, and bands ascribed to copper phases. ${ }^{51-52}$ Seven peaks are discriminated in the de-convoluted spectrum for the $150-800 \mathrm{~cm}^{-1}$ spectral region (Fig. 4c), which correspond to characteristic bands of $\mathrm{CuO}^{51}$ at 278, 334 and $601 \mathrm{~cm}^{-1}$ and smaller $\mathrm{Cu}_{2} \mathrm{O}^{52}$ peaks at 213,396, 485 and $623 \mathrm{~cm}^{-1}$, since metallic $\mathrm{Cu}$ obviously lacks of Raman bands. On the other hand, the intensity ratio of the graphitic Raman bands, D/G 1.4 (Fig. 4d), gives a common value of a partially reduced GO. ${ }^{50}$ 

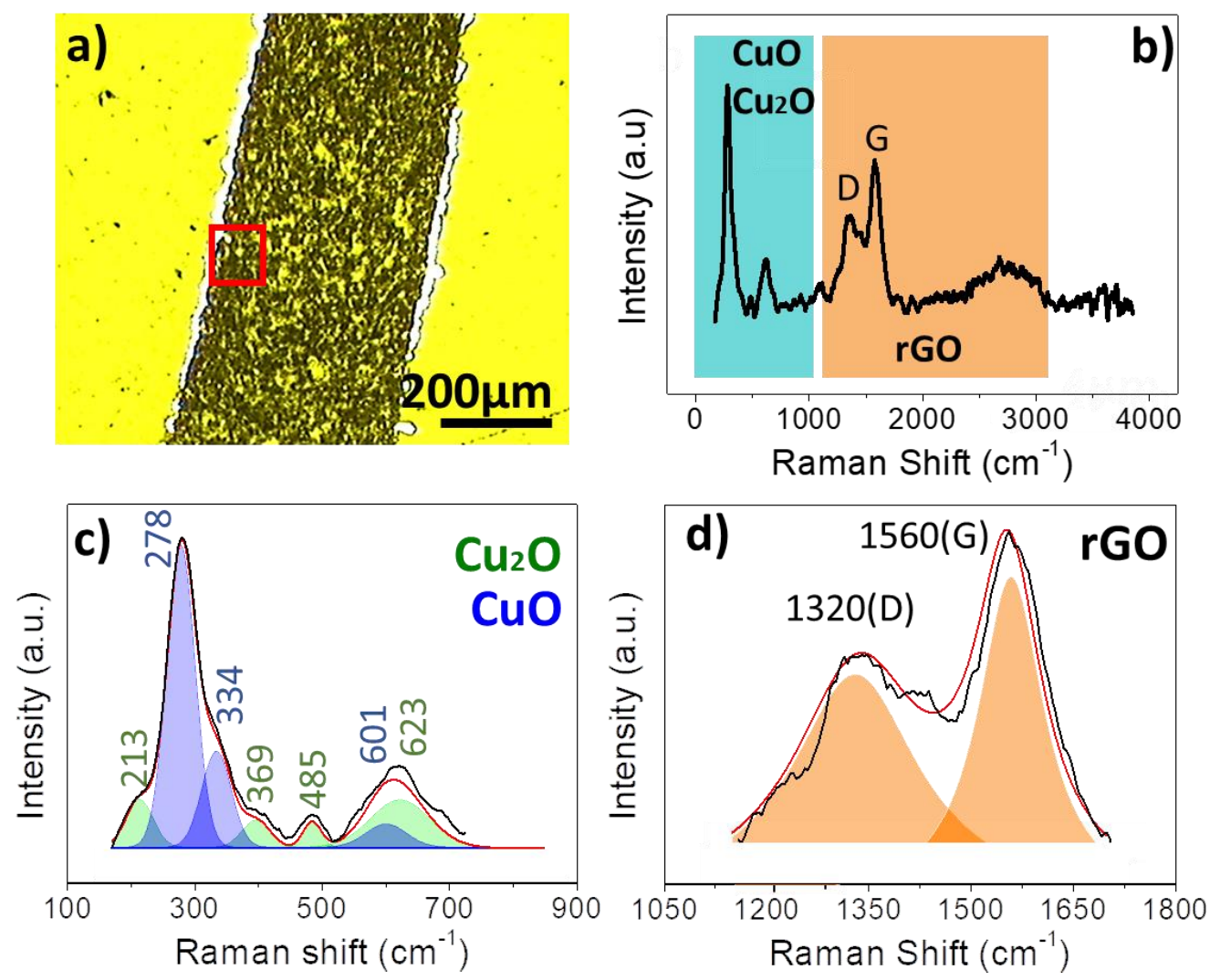

Figure 4. Optical view of a $\mathrm{Cu} / \mathrm{rGO}$ filament (polished lengthwise cross-section) (a), average Raman spectrum of the red boxed area showing spectral regions for copper oxides (green) and graphene (orange) (b), de-convoluted spectrum for spectral region of $\mathrm{Cu}_{\mathrm{x}} \mathrm{O}$ phases (c) and equally for rGO spectral region showing significant D and G bands (d).

The density of the electrodeposited samples experiences an obvious increase. By way of example, the copper phases signify around $93 \%$ of the scaffold weight and, accordingly, the bulk density increases from $0.03(\mathrm{rGO})$ to $0.42 \mathrm{~g} \cdot \mathrm{cm}^{-3}(\mathrm{Cu} / \mathrm{rGO})$. Both types of samples have the same macro-porosity $(\sim 63 \%)$ determined by the scaffold design ${ }^{53}$ according to the expression $P_{\text {macro }}=100 \cdot\left(1-\frac{\pi \emptyset^{2}}{2 a h}\right)$ where $\Phi$ is the rod diameter and $a$ and $h$ are the distances between two equivalent rods in the same plane $(a)$ and in contiguous layers $(h)$. However, the total porosity (i.e. that of the inner skeleton plus the designed macro-porosity) of the rGO structure is $\sim 98 \%$, according to the geometric 
density measurements and the theoretical density of graphene $\left(2.2 \mathrm{~g} \cdot \mathrm{cm}^{-3}\right)$, whereas the equivalent estimate for the $\mathrm{Cu} / \mathrm{rGO}$ structure gives a slightly lower porosity ( $94 \%$ ) for the coated scaffold. The theoretical density of the composite $\mathrm{Cu} / \mathrm{rGO}$ material $\left(8.4 \mathrm{~g} \cdot \mathrm{cm}^{-}\right.$ $\left.{ }^{3}\right)$ is estimated from each phase volume fraction $(0.2$ for $\mathrm{rGO}$ and 0.8 for $\mathrm{Cu})$ and the theoretical densities of $\mathrm{Cu}\left(8.96 \mathrm{~g} \cdot \mathrm{cm}^{-3}\right)$ and graphene. Image analysis on the SEM views of polished cross-sections revealed $13 \%$ porosity for the $\mathrm{Cu}$ skin, which represents only $4.7 \%$ of the rod volume; hence, the porosity of the $\mathrm{Cu} / \mathrm{rGO}$ skeleton $(\sim 31 \%)$ is chiefly located in the rod rGO core, thus giving lightness to scaffold.

Despite the obvious lightweight of both structures, they must show sufficient robustness to be considered for any reliable application. Therefore, the compression stress-strain curves were used to comparatively evaluate the mechanical integrity of both scaffolds of alike geometry. As displayed in Fig. 5a, two distinct trends are observed when comparing stress-strain plots. The rGO structures show the common response of fragile cellular materials with maximum deformations in the range of $5-10 \%$ and exhibit a relatively sudden crushing after reaching the maximum stress. This behavior differs from the high deformability displayed by some GO aerogels materials ${ }^{54,55}$ and even printed aerogels, ${ }^{56}$ which can be due to a variety of facts, including the test parameters, sample architecture and density, and the type of bonding/connectivity among the GO sheets, given by the kind of GO reduction treatment and also by the existence of functional groups..$^{55,57-58}$ On the contrary, stress-strain plots of the $\mathrm{Cu} / \mathrm{rGO}$ printed structures display the three characteristic regimes identified by Gibson and Ashby ${ }^{59}$ for both elastomeric and plastic cellular materials, i.e. a linear-elastic region at lower strains followed by plateau region of high deformation and a third region where a densification and collapse occur, which are marked in the plot for the sake of clarity (Fig. 5a). The average strength of the 3D $\mathrm{Cu} / \mathrm{rGO}$ structures $(150 \pm 10 \mathrm{kPa})$ estimated at the onset of the plateau is about one order 
of magnitude higher than that displayed by rGO scaffolds $(20 \pm 2 \mathrm{kPa})$ calculated at the maximum stress (Fig. 5a). Consequently, the $\mathrm{Cu}$ skin not only changes the type of stressstrain response but also produces a remarkable strengthening and deformability.
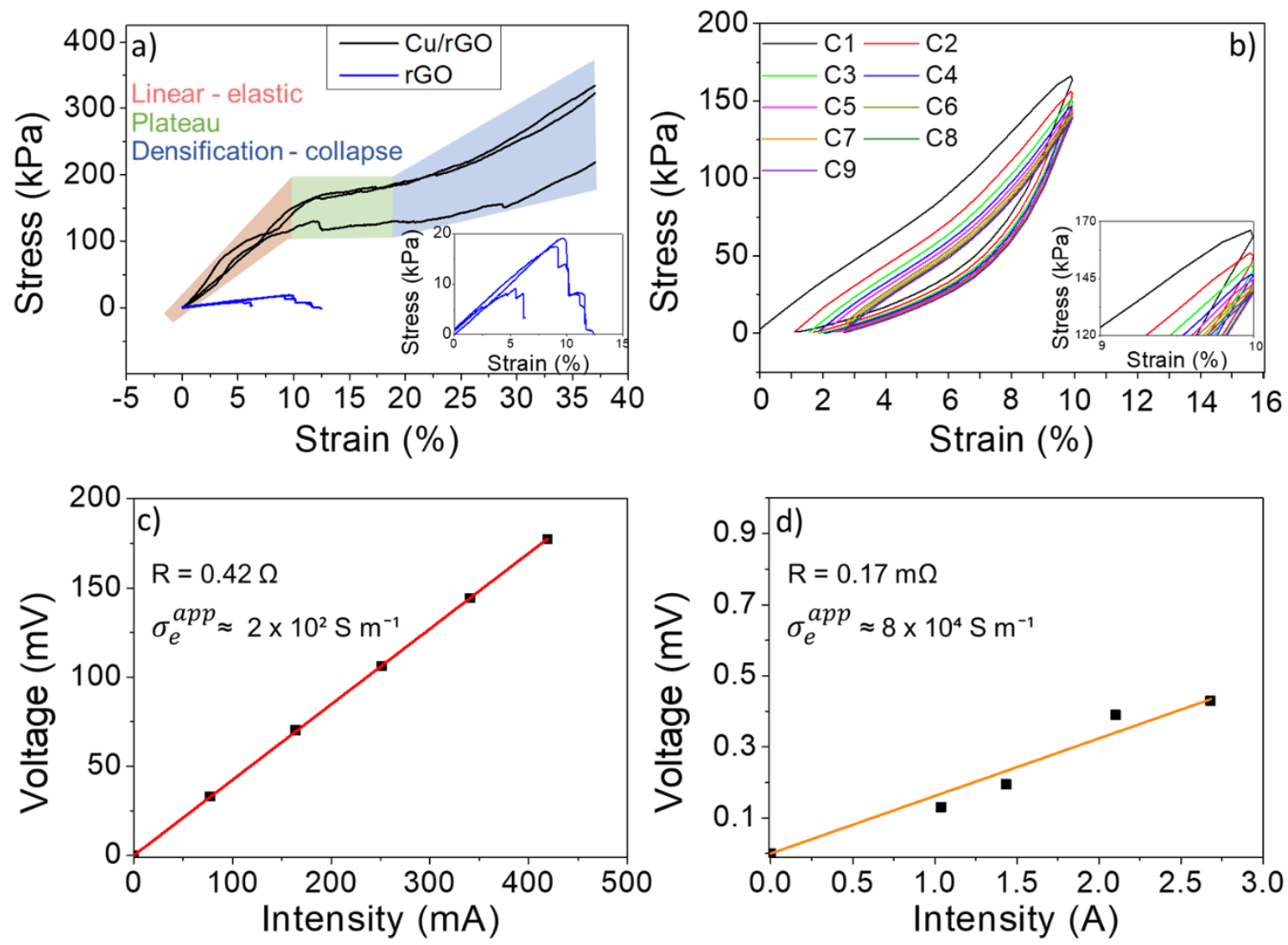

Fig. 5. Engineering stress-strain plots under compression for $\mathrm{Cu} / \mathrm{rGO}$ and $\mathrm{rGO}$ lattices (a), loading/unloading cycles of the $\mathrm{Cu}$ coated lattice (b). Voltage-intensity plots for rGO (c) and $\mathrm{Cu} / \mathrm{rGO}$ structures (d).

The effect of multiple cycling can also be seen for the $\mathrm{Cu} / \mathrm{rGO}$ structure in Fig. 5b, which illustrates how this lattice stands up to 10 cycles at $10 \%$ deformation depicting a little decay in the maximum bearing stress and relatively small permanent deformation that gives a measure of the accumulated damage. This effect is significant for TIM as they 
should be flexible and endure certain contact pressure to ensure good thermal contact. ${ }^{44,46}$ Conversely, present rGO scaffolds endured only 5 cycles under similar deformation conditions, as shown in a previous work. ${ }^{49}$

The voltage-current plots (Fig. 5c,d) reveal a much lower resistance of the coated specimen with an apparent electrical conductivity, $\sigma_{e}{ }^{\text {app }}$, in the order of $8 \times 10^{4} \mathrm{~S} \cdot \mathrm{m}^{-1}$, i.e. two orders of magnitude higher than for the bare rGO structure $\left(\sim 2 \times 10^{2} \mathrm{~S} \cdot \mathrm{m}^{-1}\right)$. The dispersion of the experimental results corresponding to the $\mathrm{Cu} / \mathrm{rGO}$ sample is associated to the very low values of voltage, owing to the high conductivity, and also, to the effect of the very high currents employed, which could in part modify the electrical behavior due to the effective annealing. The $\sigma_{\mathrm{e}}{ }^{\text {app }}$ of the $\mathrm{Cu} / \mathrm{rGO}$ structure is also higher than the reported for a $\mathrm{Cu} / \mathrm{CuO}_{\mathrm{x}}$ decorated $\mathrm{rGO}$ aerogel $\left(\sigma_{\mathrm{e}}^{\text {app }} \sim 33 \mathrm{~S} \cdot \mathrm{m}^{-1}\right)$ with $97.7 \%$ porosity $^{2}$, and it is also higher than the one measured $\left(\sigma_{\mathrm{e}}^{\text {app }} \sim 430 \mathrm{~S} \cdot \mathrm{m}^{-1}\right)$ for the compressed aerogel (porosity down to $23 \%$ ).

The electrical resistance of individual rods $\left(\mathrm{R}_{\mathrm{rod}}\right)$ can be assessed from the resistance measured in the scaffold, using the expression developed for a parallel resistor model of similar geometry, ${ }^{53} \mathrm{R}_{\mathrm{s}, \mathrm{x}}{ }^{-1}=\mathrm{n}_{\mathrm{yz}} \mathrm{R}_{\mathrm{rod}}{ }^{-1}$, where $\mathrm{R}_{\mathrm{s}, \mathrm{x}}$ and $\mathrm{R}_{\mathrm{rod}}$ are the resistances of the scaffold and the rod, respectively, the subscript $\mathrm{x}$ refers to the measurement direction and $\mathrm{n}_{\mathrm{yz}}$ indicates the number of rods aligned with the testing direction. Accordingly, using resistance data (Fig. 5c,d) and normalizing the experimental results for the same distance between the electrodes, the ratio between the corresponding rod resistances can be estimated as $\mathrm{R}_{\mathrm{rod}}^{\mathrm{GO}} / \mathrm{R}_{\mathrm{rod}} \mathrm{Cu} / \mathrm{rGO} \cong 4.3 \times 10^{2}$.

Now, assuming the coated filament as two parallel resistors (Fig. 6) and calculating its equivalent resistance, $R_{C u / r G O}^{-1}=\left(R_{r G O}^{-1}+R_{C u-s k i n}^{-1}\right)$, the following approximation $\mathrm{R}_{\text {rod }} \mathrm{Cu} / \mathrm{rGO} \cong \mathrm{R}^{\mathrm{Cu} \text {-skin }}$ is achieved from the above resistance ratio, which proves that current predominantly flows through the $\mathrm{Cu}$ layer in the coated scaffold. Consequently, the 
electrical conductivity of the $\mathrm{Cu}$ skin could be estimated as $\sigma_{\text {skin }}=\mathrm{L} /\left(\mathrm{R} \cdot \mathrm{A}_{\text {skin }}\right)$, where $\mathrm{L}$ is the distance between the probe electrodes, $\mathrm{R}$ the measured resistance and Askin the cross sectional area of the $\mathrm{Cu}$ skin (counting rods and frame), estimated according to the microstructure observations and scaffold geometry as $9.1 \times 10^{-7} \mathrm{~m}^{2}$. This estimate of the $\sigma_{\text {skin }}$ offers a value of $\sim 4.5 \times 10^{6} \mathrm{~S} \cdot \mathrm{m}^{-1}$ which, given the approximations, matches relatively well with $\sigma_{\mathrm{e}}\left(5.8 \times 10^{7} \mathrm{~S} \cdot \mathrm{m}^{-1}\right)$ of pure $\mathrm{Cu}$ films,${ }^{60}$ thus someway supporting the assumption that current mostly flows through the $\mathrm{Cu}$ skin. Note that the existence of some porosity in the skin, the presence of $\mathrm{CuO}$ and $\mathrm{Cu}_{2} \mathrm{O}$ and the uncertainty in the determination of the effective area for current flow, affect the calculated value of conductivity. Moreover, for an accurate determination of the conductivity of the skin, it would be necessary the preparation of samples with very high thickness, to improve the voltage sensibility.

a)

b)

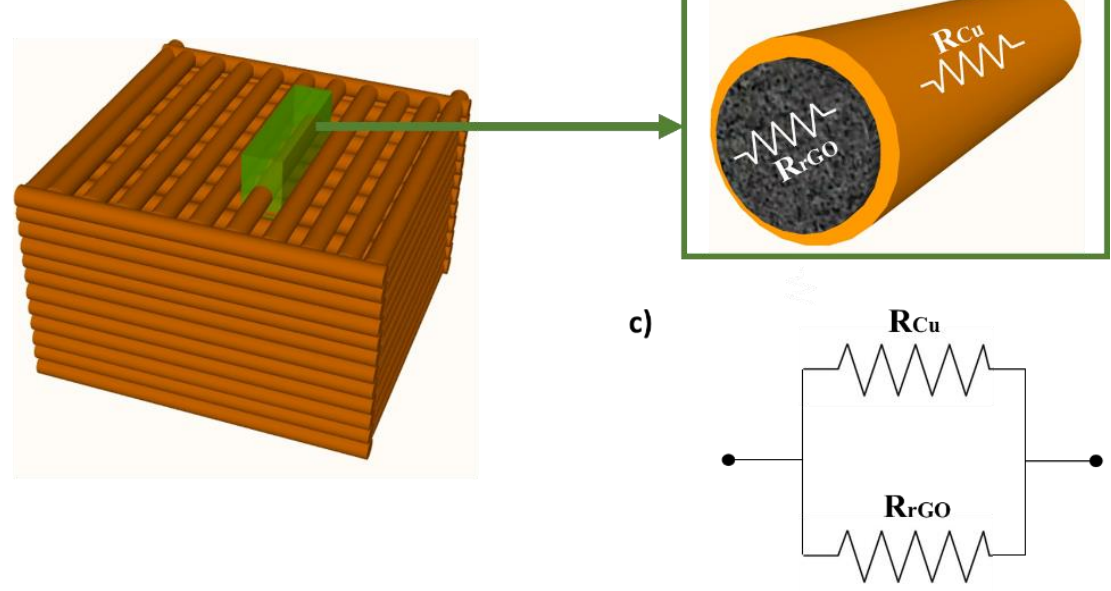

Figure 6. Scheme of the 3D Cu/rGO structure (a), drawing of a single rod cross section its rGO core and the copper coating (not to scale) with the concentric resistive elements (b), equivalent electrical circuit for the rod (c).

A comparison of the cooling curves of both scaffolds after heating them at $200{ }^{\circ} \mathrm{C}$ (type 1 test) can be seen in Fig. 7a that shows a rapid temperature decrease in the initial $15 \mathrm{~s}$ 
under free cooling conditions and with a comparatively faster cooling rate for the rGO structure $\left(77.6^{\circ} \mathrm{C} \cdot \mathrm{min}^{-1}\right)$ than for the $\mathrm{Cu} / \mathrm{rGO}$ one $\left(73.2^{\circ} \mathrm{C} \cdot \mathrm{min}^{-1}\right)$, whereas both display much slower cooling rates $\left(12\right.$ and $8{ }^{\circ} \mathrm{C} \cdot \mathrm{min}^{-1}$ for $\mathrm{rGO}$ and $\mathrm{Cu} / \mathrm{rGO}$ structures, respectively) when temperature is below $60{ }^{\circ} \mathrm{C}$. The curves in Fig. 7a can be fitted by superimposing several exponential functions with different amplitudes and time constants, which define the time range of prevalence for each function ${ }^{61}$ (more details in the Supporting information, section S4), and are mainly associated to radiation and convection heat transfer processes. The fitting parameters for the rGO scaffold (Table S1 of the Supporting information) evidence a dominant influence of the term associated to radiative cooling that practically controls the whole cooling curve, whereas for the $3 \mathrm{D}$ $\mathrm{Cu} / \mathrm{rGO}$, radiation and convective cooling compete as the two terms show comparable values during the initial part of cooling while convection clearly prevails for the remainder cooling process. This predominance of radiative cooling is reasonably explained by the higher emissivity of black bodies and the relatively larger specific surface area of the bare rGO structure $\left(\mathrm{S}_{\mathrm{BET}} \sim 65.3 \mathrm{~m}^{2} \cdot \mathrm{g}^{-1}\right.$ ) compared to the $\mathrm{Cu} / \mathrm{rGO}$ structure $\left(\mathrm{S}_{\mathrm{BET}} \sim 4.2 \mathrm{~m}^{2} \cdot \mathrm{g}^{-1}\right.$ ), since these two parameters favor radiative heat dissipation. ${ }^{62}$ 

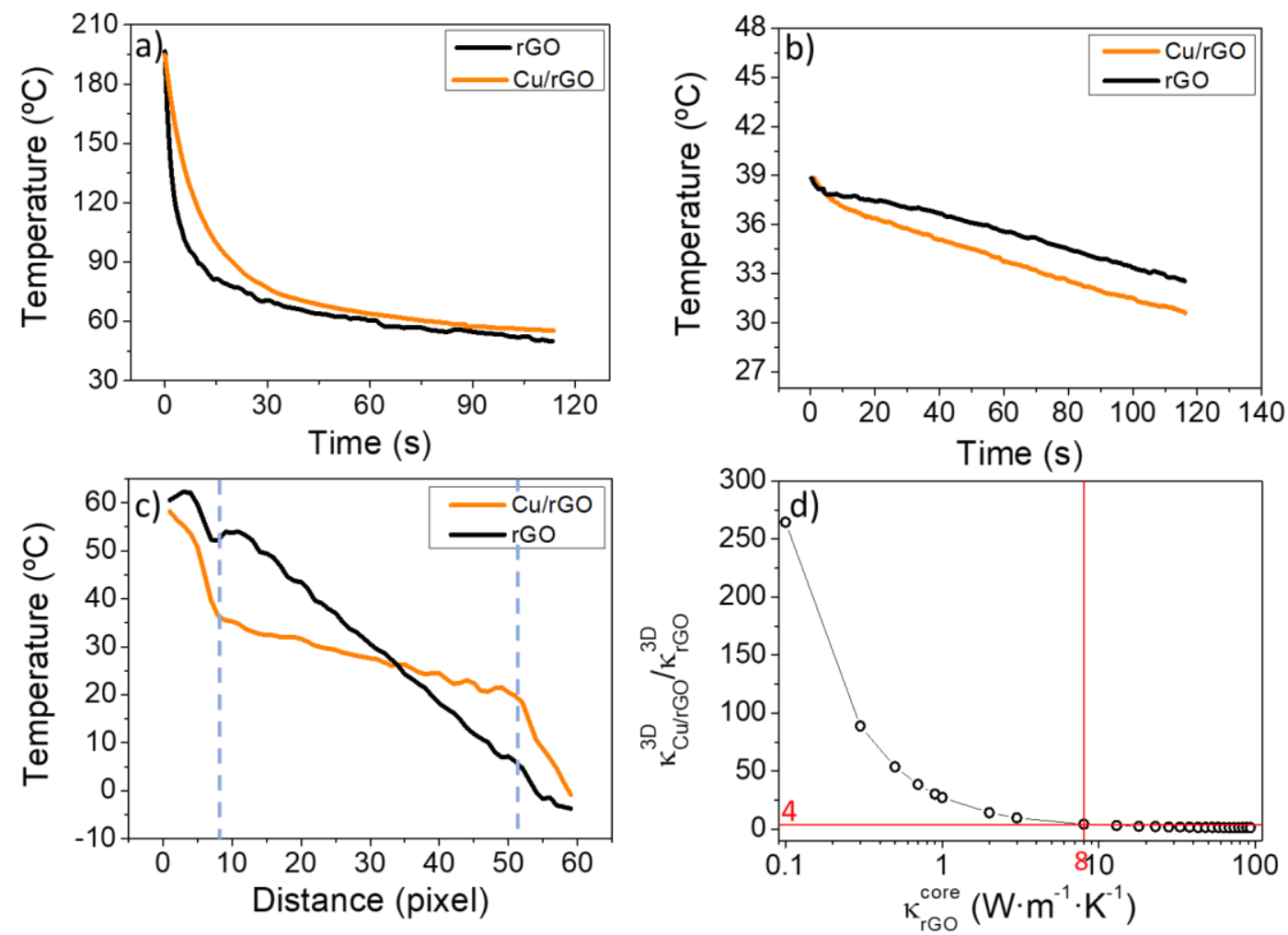

Figure 7. Temperature vs. time plots of $\mathrm{rGO}$ and $\mathrm{Cu} / \mathrm{rGO}$ structures under free cooling condition type1 (a), under conduction heat dissipation (type 2) (b), and stationary temperature profiles across both scaffolds (type 3) (c). Dotted lines mark the region for $\Delta \mathrm{T} / \Delta \mathrm{x}$ calculations. Functional variation of $\kappa^{3 D} \mathrm{Cu} / \mathrm{rGO} / \kappa^{3 D}{ }_{\mathrm{rGO}}$ with $\kappa_{r G O}^{\text {core }}(\mathrm{d})$. For $\kappa$ ratio of 4 the corresponding $\kappa_{\mathrm{rGO}}$ rod is shown $(\mathrm{d})$.

The cooling profiles of both scaffolds for the minimized convection test (type 2), which would be the conditions that applies for TIM, are compared in Fig. 7b, showing almost linear functions of time, with a comparatively faster cooling rate $\left(0.065{ }^{\circ} \mathrm{C} \cdot \mathrm{s}^{-1}\right)$ for the $\mathrm{Cu} / \mathrm{rGO}$ structure than for the $\mathrm{rGO}$ one $\left(0.050^{\circ} \mathrm{C} \cdot \mathrm{min}^{-1}\right)$. The thermal diffusivity $(\alpha)$ governs cooling rate under dynamic conditions and considering that the length and boundary conditions are equal for both samples, it is reasonable to assume that the ratio 
between both cooling rates is given by a similar ratio of $\alpha$ between both samples, accordingly $\alpha_{\mathrm{Cu} / \mathrm{rGO}}$ should be slightly higher ( 1.3 times $)$ than $\alpha_{\mathrm{rGO}}$.

On the other hand, the rGO structure exhibits a temperature gradient $(\Delta \mathrm{T} / \Delta \mathrm{x})$, under steady state conditions, of $1.3{ }^{\circ} \mathrm{C}$ per pixel that is four times higher than the measured $(0.3$ ${ }^{\circ} \mathrm{C}$ per pixel) for the $\mathrm{Cu} / \mathrm{rGO}$ structure (Fig. 7c). Accordingly, the thermal conductivity (к) of the coated structure should be $\sim 4$ times the $\kappa$ of the bare rGO.

An estimation of the apparent thermal conductivity of the structure $\left(\kappa^{3 D}\right)$ can be done using the expression of the resistor model for the present scaffold geometry parameters, ${ }^{53}$ similarly as it was done for the electrical conductivity. In this way, $\kappa^{3 D}=\frac{\varnothing}{2 a} \times \kappa^{\text {rod }}$, where $\kappa^{\text {rod }}$ is the effective thermal conductivity of a single rod. According to this equation and the parameters of the geometry, $\kappa^{3 D}$ is $\sim 0.2$ times $\kappa^{\text {rod }}$.

In the case of the $\mathrm{Cu} / \mathrm{rGO}$ sample, $\kappa^{\text {rod }}$ can be assessed from the equation $R^{\mathrm{rod}}=\mathrm{L} /\left(\kappa^{r o d} \cdot \mathrm{S}\right)$, where $\mathrm{L}$ is the resistor length, $\mathrm{S}$ is the rod section and $R^{\mathrm{rod}}$ is the equivalent thermal resistance from the model of concentric rods (Fig. 6). In this way, the following expression is deduced for the ratio between the apparent thermal conductivity of the $\mathrm{Cu} / \mathrm{rGO}$ rod and that of the rGO core:

$$
k_{C u / r G O}^{r o d} / k_{r G O}^{c o r e}=\left(S_{r G O} / S+k_{C u}^{\text {skin }} / k_{r G O}^{c o r e} \cdot S_{C u} / S\right)
$$

Areas of $\sim 1.1 \times 10^{-7}$ and $\sim 1.8 \times 10^{-10} \mathrm{~m}^{2}$ were calculated for the rGO core and the $\mathrm{Cu}$ skin, respectively, from corresponding SEM images. On the other hand, a $\kappa$ of $327 \mathrm{~W} \cdot \mathrm{m}^{-}$ ${ }^{1} \cdot \mathrm{K}^{-1}$ is estimated for the $\mathrm{Cu}$ layer using Klemens' equation, ${ }^{63}$ considering the porosity of the layer (13\%) and reported data for the theoretical ${ }^{64} \kappa \mathrm{Cu}$. From Eq (1) we can assess the variation of the $\kappa_{C u / r G O}^{r o d} / \kappa_{r G O}^{\text {core }}$ ratio for increasing values of $\kappa_{r G O}^{c o r e}$. The $\kappa$ ratio of the 
coated to bare rods $\left(\kappa^{r o d} \mathrm{Cu/rGO} / \kappa^{r o d} d_{\mathrm{rGO}}\right)$ and, equally, the $\kappa$ ratio of the corresponding $3 \mathrm{D}$ structures $\left(\kappa^{3 D} \mathrm{Cu} / \mathrm{rGO} / \kappa^{3 D} \mathrm{rGO}\right)$, show a decaying functional variation with $\kappa^{r o d_{\mathrm{rGO}}}$ (Fig. 7d); that is, the effect of the $\mathrm{Cu}$ skin on increasing thermal conductivity strongly augments as the thermal conductivity of the rGO rod decreases, as it would be the case of lower density cores of more defective GO sheets.

Bearing in mind the ratio $\kappa^{3 D} \mathrm{Cu} / \mathrm{rGO} / \kappa^{3 D}$ rGO $\cong 4$ measured in stationary conditions, a $\kappa_{\mathrm{rGO}}$ $\cong 8 \mathrm{~W} \mathrm{~m}^{-1} \mathrm{~K}^{-1}$ is calculated, and so, a $\kappa^{3 D}{ }_{\mathrm{rGO}} \sim 1.3 \mathrm{~W} \mathrm{~m}^{-1} \mathrm{~K}^{-1}$ for the whole scaffold. The latter thermal conductivity perfectly agrees with the $\kappa$ value $\left(\sim 2 \mathrm{~W} \mathrm{~m}^{-1} \mathrm{~K}^{-1}\right)$ reported for open cell graphene foams of equal density $\left(\rho \sim 0.03 \mathrm{~g} \mathrm{~cm}^{-3}\right)$, grown by CVD on Ni foams, after Ni leaching. ${ }^{65}$

The above results prove that the $\mathrm{Cu}$ skin $(\sim 20 \mu \mathrm{m}$ thick $)$ significantly enhances the thermal conductivity ( $\sim 4$ times) of bare rGO scaffolds, which is interesting for applications requiring improved heat dissipation for all kinds of compact electronic devices.

\section{Conclusions}

Architected $\mathrm{Cu} / \mathrm{rGO}$ structures are achieved by a relatively simple, low cost and adaptable procedure consisting on electrodepositing $\mathrm{Cu}$ on 3D printed rGO scaffolds. Electroplating produced a thin $\mathrm{Cu}$ layer of $\sim 20 \mu \mathrm{m}$ outlining the bare rGO scaffold that practically controls its mechanical, electrical and thermal capabilities. The 3D $\mathrm{Cu} / \mathrm{rGO}$ structure possesses obvious advantages as it is lightweight, mechanically more stable and flexible than the bare rGO scaffold and shows enhanced electrical (400 times higher) and thermal conductivities (4 times higher), particularly, this heterostructure seems suitable as TIM because the enhanced heat dissipation by thermal conduction. The shown method is a proof concept since it could be applied to different types of graphitic structures (GO, 
GNP, fibers, CNT and mixtures), and for other types of metallic and composite skins as well, which certainly extends the range of possible applications.

\section{Acknowledgements}

This work was supported by Spanish project RTI2018-095052-B-I00 (MCIU/AEI/FEDER, UE). JJM acknowledges the financial support of MCIU through the FPI contract ref: BES-2016-077759.

\section{Supporting Information}

Experimental setting for electrical conductivity measurement and thermal cooling tests for 3D samples.

Tomographic projections and XRD pattern of the coated structures

Fitting of the temperature profiles under free cooling conditions for the bare and coated samples

\section{References}

(1) Mirzaee, M; Dehghanian, C; Sabet Bokati, K. One-Step Electrodeposition of Reduced Graphene Oxide on Three-Dimensional Porous Nano Nickel-Copper Foam Electrode and Its Use in Supercapacitor, J. Electroanal. Chem. 2018, 813,152-162. https://doi.org/10.1016/j.jelechem.2018.02.032.

(2) Zhao, J; Pan, R; Sun, R. High-Conductivity Reduced-Graphene-Oxide/Copper Aerogel for Energy Storage, Nano Energy 2019, 60, 760-767. https://doi.org/10.1016/j.nanoen.2019.04.023.

(3) Perreault, L. L.; Colò, F.; Meligrana, G.; Kin, K.; Fiorilli, S.; Bella, F.; Nair, J. R.; Vitale-Brovarone, C.; Florek, J.; Kleitz, F. Stray-Dried Mesoporous Mixed Cu-Ni 
Oxide@Graphene Nanocomposite Microspheres for High Power and Durable Li-Ion Battery Anodes. Adv. Energy Mater. 2018, 8, 1802438. https://doi.org/10.1002/aenm.201802438.

(4) Fagiolari, L.; Bella, B. Carbon-Based Materials for Stable, Cheaper and LargeScale Processable Perovskite Solar Cells. Energ. Environ. Sci. 2019, 12, 3437 - 3472. https://doi.org/10.1039/c9ee02115a

(5) Bashir, A.; Lew, J. H.; Shukla, S.; Gupta, D.; Baikie, T.; Chakraborty, S.; Patidar, R.; Bruno, A.; Mhaisalkar, S.; Akhter, Z. Cu-doped Nickel Oxide Interface Layer with Nanoscale Thickness for Efficient and Highly Stable Printable Carbon-Bases Perovskite Solar Cell. Sol. Energy 2019, 182, 225-236. https://doi.org/10.1016/j.solener.2019.02.056

(6) Devnani, H.; Rashid, N.; Ingole, P.P. Copper/Cuprous Oxide Nanoparticles Decorated Reduced Graphene Oxide Sheets Based Platform for Bio-Electrochemical Sensing of Dopamine. Chemistry Select 2019, 4, 633-643. https://doi.org/10.1002/slct.201803233.

(7) Li, J.; Jiang, J.; Xu, Z.; Liu, M.; Tang, S.; Yang, C.; Qian, D. Facile Synthesis of Pd-Cu@Cu2O/N-RGO Hybrid and its Application for Electrochemical Detection of Tryptophan. Electrochim. Acta 2018, 260, 526-535. https://doi.org/10.1016/j.electacta.2017.12.125.

(8) Li, Y.; Cui, F.; Ross, M. B.; Kim, D.; Sun, Y.; Yang, P. Structure-Sensitive CO2 Electroreduction to Hydrocarbons on Ultrathin 5-fold Twinned Copper Nanowires, Nano Lett. 2017, 17, 1312-1317. https://doi.org/10.1021/acs.nanolett.6b05287.

( 9) Shown, I.; Hsu, H. C.; Chang, Y. C.; Lin, C. H.; Roy, P. K.; Ganguly, A.; Wang, C. H.; Chang, J. K.; Wu, C. I.; Chen, L. C.; Chen, K. H. Highly Efficient Visible Light 
Photocatalytic Reduction of $\mathrm{CO} 2$ to Hydrocarbon Fuels by $\mathrm{Cu}-\mathrm{Nanoparticle} \mathrm{Decorated}$ Graphene Oxide. Nano Lett. 2014, 14, 6097-6103. https://doi.org/10.1021/nl503609v.

(10) Huan, N. T.; Dalla-Corte, D. A.; Lamaison, S.; Karapinar, D.; Lutz, L.; Menguy, N.; Foldyna, M.; Turren-Cruz, S. H.; Hagfeldt, A. Bella, F.; Fontecave, M.; Mougel, V. Low-Cost High-Efficiency Systems for Solar-Driven Conversion of $\mathrm{CO} 2$ to Hydrocarbons. P. Natl. Acad. Sci. USA 2019, 116, 9735 - 9740. https://doi.org/10.1073/pnas.1815412116.

(11) Hsieh, C. T.; Chen, Y.F.; Lee, C. E.; Chiang, Y. M.; Hsieh, K. Y.; Wu, H. S. Heat Transport Enhancement of Heat Sinks Using Cu-Coated Graphene Composites. Mater. Chem. Phys. 2017, 197, 105-112. https://doi.org/10.1016/j.matchemphys.2017.05.012.

(12) Rho, H.; Lee, S.; Bae, S.; Kim, T. W.; Lee, D. S.; Lee, H. J.; Hwang, J. Y.; Jeong, T.; Kim, S.; Ha, J. S.; Lee, S. H. Three-Dimensional Porous Copper-Graphene Heterostructures with Durability and High Heat Dissipation Performance. Sci. Rep. 2015, 5, 1-7. https://doi.org/10.1038/srep12710.

(13) Shtein, M.; Nadiv, R.; Buzaglo, M.; Regev, O. Graphene-Based Hybrid Composites for Efficient Thermal Management of Electronic Devices, ACS Appl. Mater. Interfaces 2015, 7, 23725-23730. https://doi.org/10.1021/acsami.5b07866.

(14) Rishi, A. M.; Kandlikar, S. G.; Gupta, A. Improved Wettability of Graphene Nanoplatelets (GNP)/Copper Porous Coatings for Dramatic Improvements in Pool Boiling Heat Transfer, Int. J. Heat Mass Transf. 2019, 132, 462-472. https://doi.org/10.1016/j.ijheatmasstransfer.2018.11.169.

(15) Hidalgo-Manrique, P.; Lei, X.; Xu, R.; Zhou, M.; Kinloch, I. A.; Young, R. J. Copper/Graphene Composites: A Review, J. Mater. Sci. 2019, 54, 12236-12289. https://doi.org/10.1007/s10853-019-03703-5. 
(16) Chu, K.; Wang, X. H.; Li, Y. B.; Huang, D. J.; Geng, Z. R.; Zhao, X. L.; Liu, H.; Zhang, H. Thermal Properties of Graphene/Metal Composites with Aligned Graphene. Mater. Design. 140 (2018) 85-94. https://doi.org/10.1016/j.matdes.2017.11.048.

(17) Mattevi, C.; Kim, H.; Chhowalla, M. A Review of Chemical Vapour Deposition of Graphene on Copper, J. Mater. Chem. 2011, 21, 3324-3334. https://doi.org/10.1039/c0jm02126a.

(18) Pavithra, C. L. P.; Sarada, B. V.; Rajulapati, K. V.; Rao, T. N.; Sundararajan, G. A New Electrochemical Approach for the Synthesis of Copper-Graphene Nanocomposite Foils with High Hardness, Sci. Rep. 2014, 4, 1-7. https://doi.org/10.1038/srep04049.

(19) Pingale, A. D.; Belgamwar, S. U.; Rathore, J. S. Synthesis and Characterization of $\mathrm{Cu}-\mathrm{Ni} / \mathrm{Gr}$ Nanocomposite Coating by Electro-co-Deposition Method: Effect of Current Density. B. Mater. Sci. 2020, 43, 66. https://doi.org/10.1007/s12034-019-2031-x.

(20) Peng, P.; Li, L.; He, P.; Zhu, Y.; Fu, J.; Huang, Y.; Guo, W. One-Step Selective Laser Pattering of Copper/Graphene Flexible Electrodes. Nanotechnology 2019, 30, 185301. https://doi.org/10.1088/1361-6528/aafe4c.

(21) Mussa, Y.; Ahmed, F.; Arsalan, M.; Alsharaeh, E. Two Dimensional (2D) Reduced Graphene Oxide (RGO)/Hexagonal Boron Nitride ( $h$-BN) Based Nanocomposites as Anodes for High Temperature Rechargeable Lithium-Ion Batteries. Sci. Rep. 2020, 10, 1882 doi.org/10.1038/s41598-020-58439-z

(22) Zheng, L.; Zheng, H.; Hou, D.; Wu, F.; Shao, L.; Zheng, P.; Jiang, Y.; Zheng, X.; Qui, X.; Liu, Y.; Zhang, Y. N-Doped Graphene-Based Copper Nanocomposite With Ultralow Electrical Resistivity and High Thermal Conductivity. Sci. Rep. 2018, 8, 9248. https://doi.org/10.1038/s41598-018-27667-9 
(23) Wu, s.; Yin, z.; He, Q.; Lu, G.; Zhou, X.; Zhang, H. Electrochemical Deposition of Cl-doped N-type $\mathrm{Cu} 2 \mathrm{O}$ on Reduced Graphene Oxide Electrodes. J. Mater. Chem. 2011, 21, 3467-3470. https://doi.org/10.1039/c0jm02267e.

(24) Su, Y.W.; Wu, C.S.; Liu, C.H.; Lin, H.Y.; Chen, C.D. Hybrid Stacking Structure of Electroplated Copper onto Graphene for Future Interconnect Applications. Appl. Phys. Lett. 2015, 107, 093105. https://doi.org/10.1063/1.4930154.

(25) Jaikumar, A.: Santhanam1, K. S. V.; Kandlikar, S.G.; Raya, I.B.P.; Raghupathi, P. Electrochemical Deposition of Copper on Graphene with High Heat Transfer Coefficient. ECS Transactions. 2015, 66, 55-64. https://doi.org/10.1149/06630.0055ecst (26) Lamberti, A.; Gigot, A.; Bianco, S.; Fontana, M.; Castellino, M.; Tresso, E.; Pirri C.F. Self-Assembly of Graphene Aerogel on Copper Wire for Wearable Fiber-shaped Supercapacitors. Carbon 2016, 105, 649-654. https://doi.org/10.1016/j.carbon.2016.05.003.

(27) Pedico, A.; Lamberti, A.; Gigot, A.; Fontana, M.; Bella, F.; Rivolo, P.; Cocuzza, M.; Pirri, C. F. High-Performing and Stable Wearable Supercapacitor Exploiting rGO Aerogel Decorated with Copper and Molybdenum Sulfides on Carbon Fibers. ACS Appl. Energy Mater. 2018, 1, 4440-4447. https://doi.org/10.1021/acsaem.8b00904.

(28) Qui, Z.; Jung, G. S.; Kang, M. J.; Buehler, M. J. The Mechanics and Design f a Lightweight Three-Dimensional Graphene Assembly. Sci. Adv. 2017, 3, e1601536. https:// 10.1126/sciadv.1601536.

(29) Rocha, V. G.; García-Tuñon, E.; Botas, C.; Markoulidis, F.; Feilden, E.; D’Elia, E.; Ni, N.; Shaffer, M.; Saiz, E. Multimaterial 3D Printing of Graphene-Based Electrodes for Electrochemical Energy Storage Using Thermoresponsive Inks. ACS Appl. Mater. Interfaces 2017, 9, 37136-37145, https://doi.org/10.1021/acsami.7b10285. 
(30) Mooraj, S.; Welborn, S. S.; Jiang, S.; Peng, S.; Fu, J.; Baker, S.; Duoss, E. B.;

Zhu, C.; Detsi, E.; Chen, W. Three-Dimensional Hierarchical Nanoporous Copper via

Direct Ink Writing and Dealloying. Scripta Mater. 2020, 177, 146-150. https://doi.org/10.1016/j.scriptamat.2019.10.013

(31) Zhu, C.; Han, T. Y. J.; Duoss, E. B.; Golobic, A. M.; Kuntz, J. D.; Spadaccini, C. M.; Worsley, M. A. Highly Compressible 3D Periodic Graphene Aerogel Microlattices. Nat. Commun. 2015, 6, 1-8. https://doi.org/10.1038/ncomms7962.

(32) García-Tuñón, E.; Barg, S.; Franco, J.; Bell, R.; Eslava, S.; D’Elia, E.; Maher, R. C.; Guitian, F.; Saiz, E. Printing in Three Dimensions with Graphene. Adv. Mater. 2015, 27, 1688-1693. https://doi.org/10.1002/adma.201405046.

(33) Zhang Q; Zhang F, Medarametla S. P.; Li H; Zhou C; Lin D. 3D Printing of $\begin{array}{lllll}\text { Graphene } & \text { Aerogels. } & \text { Small } & \text { 2016, }\end{array}$ https://doi.org/10.1002/smll.201503524.

(34) De La Osa, G.; Pérez-Coll, D.; Miranzo, P.; Osendi, M. I.; Belmonte, M. Printing of Graphene Nanoplatelets into Highly Electrically Conductive Three-Dimensional Porous Macrostructures. Chem. Mater. 2016, 28, 6321-6328. https://doi.org/10.1021/acs.chemmater.6b02662.

(35) Moyano J. J.; Gómez-Gómez, A.; Pérez-Coll, D.; Belmonte, M.; Miranzo, P.; Osendi, M. I. Filament Printing of Graphene-Based Inks into Self-Supported 3D Architectures. Carbon 2019, 151, 94-102. https://doi.org/10.1016/j.carbon.2019.05.059. (36) Grujicic, D.; Pesic, B. Electrodeposition of Copper: The Nucleation Mechanisms. Electrochim. Acta 2002, 47, 2901-2912. https://doi.org/10.1016/S0013-4686(02)00161- 
(37) Ghodbane, O.; Roué, L.; Bélanger, D. Copper Electrodeposition on Pyrolytic Graphite Electrodes: Effect of the Copper Salt on the Electrodeposition Process. Electrochim. Acta 2007, 52, 5843-5855. https://doi.org/10.1016/j.electacta.2007.03.009 (38) Hannula, P. M.; Peltonen, A.; Aromaa, J.; Janas, D.; Lundström, M.; Wilson, B. P.; Koziol, K.; Forsén, O. Carbon Nanotube-Copper Composites by Electrodeposition on Carbon Nanotube Fibers. Carbon 2016, 107, 281-287. https://doi.org/10.1016/j.carbon.2016.06.008.

(39) Xu, G.; Zhao, J.; Li, S.; Zhang, X.; Yong, Z.; Li, Q. Continuous Electrodeposition for Lightweight, Highly Conducting and Strong Carbon Nanotube-Copper Composite Fibers. Nanoscale 2011, 3, 4215-4219. https://doi.org/10.1039/c1nr10571j.

(40) Subramaniam, C.; Yamad, T.; Kobashi, K.; Sekiguchi, A.; Futaba, D. N.; Yumura, M. One-Hundred-Fold Increase in Current Carrying Capacity in a Carbon NanotubeCopper Composite. Nat. Commun. 2013, 4, 2202. https://doi.org/10.1038/ncomms3202 (41) Beica, R.Through silicon via copper electrodeposition for 3D integration, in: 58th Electron. Components Technol. Conf., Lake Buena Vista, 2008, 577-583. https://doi.org/10.1109/ECTC.2008.4550031.

(42) Menk, L. A.; Baca, E.; Blain, M. G.; McClain, J.; Dominguez, J.; Smith, A.; Hollowell, E. Galvanostatic Plating with a Single Additive Electrolyte for Bottom-Up Filling of Copper in Mesoscale TSVs. J. Electrochem. Soc. 2019, 166, D3226. https://doi.org/10.1149/2.0271901jes

(43) Feng, C. P.; Chen, L. B.; Tian, G. L.; Wan, S. S.; Bai, L.; Bao, R. Y.; Liu, Z. Y.; Yang, M. B.; Yang, W. Multifunctional Thermal Management Materials with Excellent Heat Dissipation and Generation Capability for Future Electronics. ACS Appl. Mater. Interfaces 2019, 11, 18739-18745. https://doi.org/10.1021/acsami.9b03885. 
(44) Dai, W.; Ma, T.; Yan, Q.; Gao, J.; Tan, X.; Lv, L.; Hou H.; Wei, Q.; Yu, J.; Wu, J.; Yao, Y.; Du, S.; Sun, R.; Jiang, N.; Wang, Y.; Kong, J.; Wong, C.; Maruyama S.; Lin, C. T. Metal-Level Thermally Conductive yet Soft Graphene Thermal Interface Materials, ACS Nano 2019, 13, 11561-11571. https://doi.org/10.1021/acsnano.9b05163.

(45) Loeblein, M.; Leong, F. N.; Tsang, S. H.; Huat, L. L.; Teo, J. W. R.; Teo, E. H. T. Reliability Studies of a Super-Durable 3-D-Foam-Based TIM for All Environments. IEEE Transactions on Device and Materials Reliability 2018,18, 273-278. https://doi.org/10.1109/TDMR.2018.2829156

(46) Zhang, X.; Yeung, K. K.; Gao, Z.; Li, J.; Sun, H.; Xu, H.; Zhang, K.; Zhang, M.; Chen, Z.; Yuen, M. M. F.; Yang, S. Exceptional Thermal Interface Properties of a ThreeDimensional Graphene Foam. Carbon 2014, 66, 201-209. https://doi.org/10.1016/j.carbon.2013.08.059

(47) Alemour, B.; Badran, O.; Hassan, M. R. A Review of Using Conductive Composite Materials in Solving Lightering Strike and Ice Accumulation Problems in Aviation. J. Aerosp. Technol. Manag. 2019, 11, e1919. https://doi.org/10.5028/jatm.v11.1022

(48) Kumar, S. S. A.; Uddin, M. N.; Rahman, M. M.; Ashmatulu, R. Introducing Graphene Thin Films into Carbon Fiber Composite Structures for Lightning Strike Protection. Polym. Composites 2019, 40, E517-E525. https://doi.org/10.1002/pc.24850. (49) Moyano, J. J.; Mosa, J.; Aparicio, M.; Pérez-Coll, D.; Belmonte, M.; Miranzo, P.; Osendi, M.I. Strong and Light Cellular Silicon Carbonitride - Reduced Graphene Oxide Material with Enhanced Electrical Conductivity and Capacitive Response. Addit. Manuf. 2019, 30, 100849. https://doi.org/10.1016/j.addma.2019.100849.

(50) Ni, Z.; Wang, Y.; Yu, T.; Shen Z. Raman Spectroscopy and Imaging of Graphene. Nano Res. 2008, 1, 273-291. https://doi.org/10.1007/s12274-008-8036-1. 
(51) Wang, W.; Zhou, Q.; Fei, X.; He, Y.; Zhang, P.; Zhang, G.; Peng, L.; Xie, W. Synthesis of CuO Nano- and Micro-Structures and Their Raman Spectroscopic Studies. CrystEngComm. 2010, 12, 2232-2237. https://doi.org/10.1039/b919043k.

(52) Singhal, A.; Pai, M. R.; Rao, R.; Pillai, K. T.; Lieberwirth, I.; Tyagi, A. K. Copper(I) Oxide Nanocrystals - One Step Synthesis, Characterization, Formation Mechanism, and Photocatalytic Properties. Eur. J. Inorg. Chem. 2013, 2013, 2640-2651. https://doi.org/10.1002/ejic.201201382.

(53) Román-Manso, B.; Figueiredo, F. M.; Achiaga, B.; Barea, R.; Pérez-Coll, D.; Morelos-Gómez, A.; Terrones, M.; Osendi, M. I.; Belmonte, M.; Miranzo, P. Electrically Functional 3D-Architectured Graphene/SiC Composites, Carbon 2016, 100, 318-328. https://doi.org/10.1016/j.carbon.2015.12.103.

(54) Wu, Y.; Yi, N.; Huang, L.; Zhang, T.; Fang, S.; Chang, H.; Li, N.; Oh, J.; Lee, J. A.; Lozlov, M.; Chipara, A. C.; Terrones, H.; Xiao, P.; Long, G.; Huang, Y.; Zhang, F.; Zhang, L.; Lepró, X.; Haines, C.; Lima, M. D.; Perea-Lopez, N.; Rajukumar, L. P.; Elias, A. 1.; Feng, S.; Kim, S. J.; Narayanan N. T.; Ajayan P. M.; Terrones, M.; Aliev, A.; Chu, P.; Chang, Z.; Baughman R. H.; Chen, Y. Three-Dimensional Bonded Spongy Graphene Material with Super Compressive Elasticity and Near-Zero Poisson's Ratio. Nat. Commun. 2015, 6, 6141. https://doi.org/10.1038/ncomms7141.

(55) Yang, M.; Zhao, N.; Cui, Y.; Gao, W.; Zhao, Q.; Gao, C.; Bai, H.; Xie, T. Biomimetic Architectured Graphene Aerogel with Exceptional Strength and Resilience. ACS Nano 2017, 11, 6817-6824. https://doi.org/10.1021/acsnano.7b01815.

(56) Jiang, Y.; Xu, Z.; Huang, T.; Liu, Y.; Guo, F.; Xi, J.; Gao, W.; Gao, C. Direct 3D Printing of Ultralight Graphene Oxide Aerogel Microlattices. Adv. Funct. Mater. 2018, 28, 1707024. https://doi.org/10.1002/adfm.201707024 
(57) Barg, S.; Macul Perez, F.; Ni, N.; Do Vale Pereira, P.; Maher, R. C.; GarciaTuñon, E.; Eslava, S.; Agnoli, S.; Mattevi, C.; Saiz, E. Mesoscale Assembly of Chemically Modified Graphene into Complex Cellular Networks. Nat. Commun. 2014, 5, 4328. https://doi.org/10.1038/ncomms53289.

(58) Zhuo, H.; Hu, Y.; Chen, Z.; Zhong, L.; Lai, H.; Liu, L.; Jing, S.; Liu, Q.; Liu C.; Peng, X.; Sun, R. A Supercompressible, Elastic, and Bendable Carbon Aerogel with Ultrasensitive Detection Limits for Compression Strain, Pressure, and Bending Angle. Adv. Mater. 2018, 30, 1706705. https://doi.org/10.1002/adma.201706705.

(59) L.J. Gibson, M.F. Ashby, Cellular Ceramics, 2001.

(60) Lide, D. R. (ed.). Handbook of Chemistry and Physics, 84th ed., CRC Press, 2004.

(61) Vollmer, M. Newton's Law of Cooling Revisited. Eur. J. Phys. 2009, 30, 10631084. https://doi.org/10.1088/0143-0807/30/5/014.

(62) Gómez-Gómez A., Moyano J.J., Román-Manso B., Belmonte M., Miranzo P., Osendi M.I., Highly-porous Hierarchical SiC structures Obtained by Filament Printing and Partial Sintering, J. Eur. Ceram. Soc. 39 (2019) 688-695. https://doi.org/10.1016/j.jeurceramsoc.2018.12.034

(63) P. G. Klemens, "Thermal Conductivity in Homogeneous Media," High TempsHigh Press, vol. 23, pp. 241-248, 1991

(64) H. D. Young, University Physics, 7th ed. Addison Wesley, 1992.

(65) Pettes, M. T.; Ji, H.; Ruoff, R. S.; Shi, L. Thermal Transport in Three-Dimensional Foam Architectures of Few-Layer Graphene and Ultrathin Graphite. Nano Lett. 2012, 12, 2959-2964. https://doi.org/10.1021/nl300662q. 


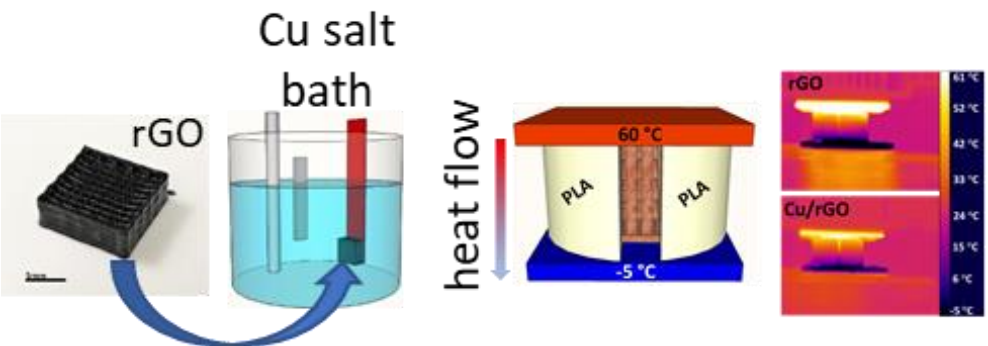




\section{Supporting Information}

The remarkable effects of an electrodeposited copper skin on the strength, and the electrical and thermal conductivities of reduced graphene oxide printed scaffolds

Juan José Moyano ${ }^{1}$, Iñaki Garcia ${ }^{2}$, Juan de Damborenea ${ }^{2}$, Domingo Pérez-Col1 ${ }^{1}$, Manuel Belmonte ${ }^{1}$, Pilar Miranzo ${ }^{1}$, Maria Isabel Osendi ${ }^{*}$

${ }^{1}$ Instituto de Cerámica y Vidrio, CSIC, Campus de Cantoblanco, 28049 Madrid, Spain

${ }^{2}$ Centro Nacional de Investigaciones Metalúrgicas CENIM-CSIC, av. Gregorio del Amo 8, 28040 Madrid, Spain

*corresponding author E-mail address: miosendi@icv.csic.es 


\section{S1. Electrical conductivity measurement set-up and thermal-cooling rigs employed}

a)

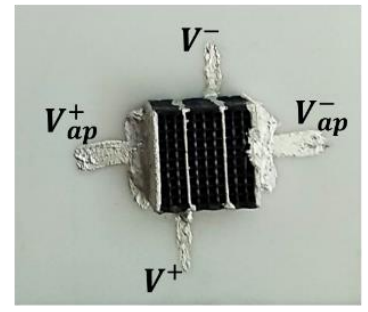

c)

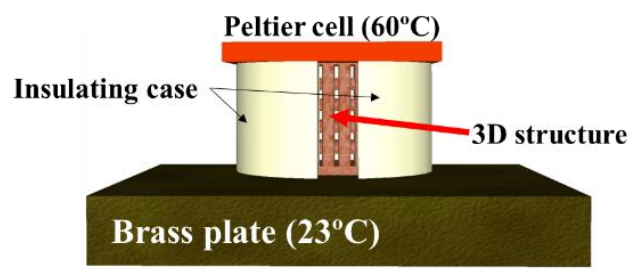

b)

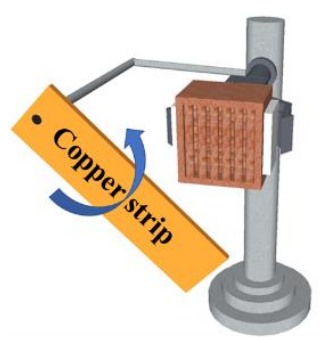

d)

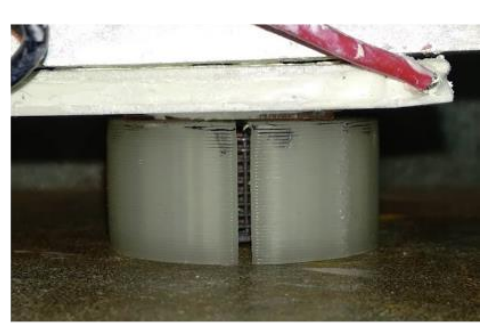

Figure S1. Experimental setup for the electrical measurement of the scaffold with the 4 painted $\mathrm{Ag}$ electrodes for voltage application and measurement (a), drawing of the rigging used for indirectly heating (through a copper screen) the 3D sample with a butane/air micro-torch at $\mathrm{T} \sim 200^{\circ} \mathrm{C}$ (b), schematics of the heating/cooling tests ( type 2) within the insulating case for predominant thermal conduction cooling (c), image of the real setting with the insulating polymer (polylactic acid, PLA) case (d).

\section{S2. Tomographic sections of $\mathrm{Cu} / \mathrm{rGO}$ sample}
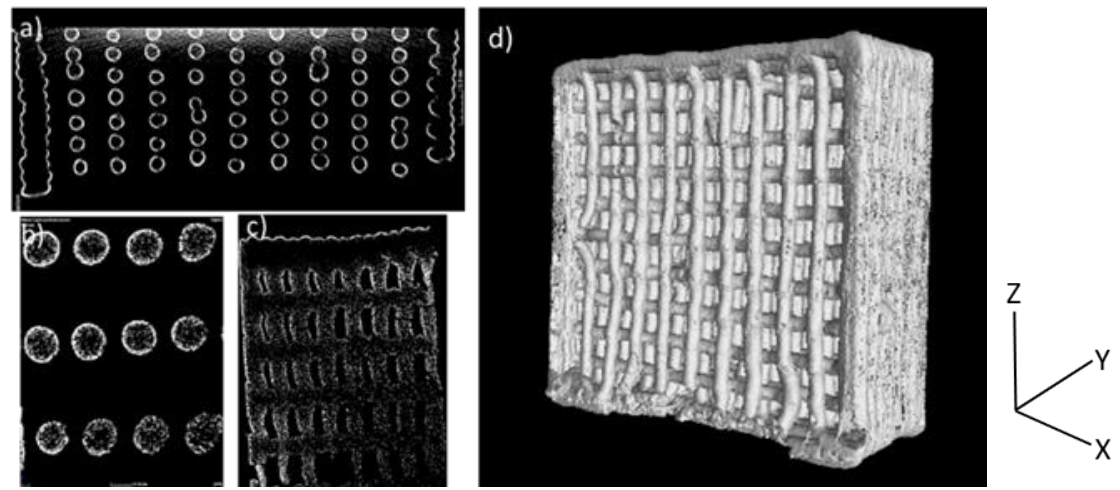

Figure S2. Tomographic images of $\mathrm{Cu} / \mathrm{rGO}$ sample showing the $\mathrm{Cu}$ profiling: cross section on y-z plane (a), detailed scan of the same section (b), detailed scan near the structure frame (c) isometric projection of the entire structure (d). 


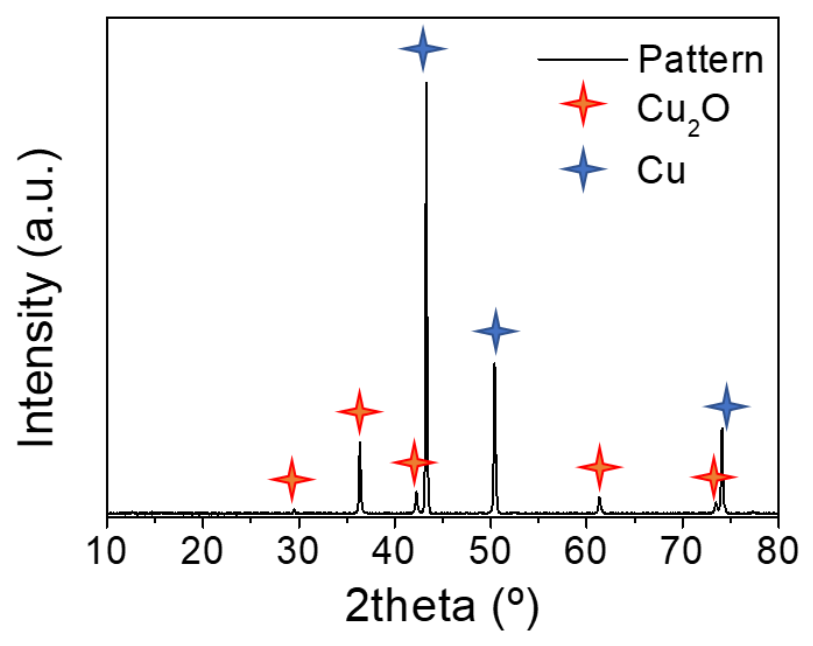

Figure S3. XRD pattern from the surface of the $\mathrm{Cu} / \mathrm{rGO}$ scaffold with corresponding phase adscriptions.

\section{S4. Fitting the free cooling of the scaffolds}

The free cooling of a solid can be normally fitted by superimposing exponential functions of different amplitudes and time constants, ${ }^{1}$ for present structures the sum of two exponential functions as in Eq. 1 provides good fitting:

$$
T(t)=T_{0}+A_{1} \cdot e^{-t / \tau_{1}}+A_{2} \cdot e^{-t / \tau_{2}}
$$

The fitting parameters for the rGO scaffold (Table S1) cooling curve (Fig. 7a of the paper) evidence a dominant influence of the first term $\left(A_{1}>A_{2}\right)$, which practically controls the whole cooling curve and can be associated to a radiative cooling term. ${ }^{1-2}$

In opposition, the $\mathrm{Cu} / \mathrm{rGO}$ structure (Table $\mathrm{S} 1$ ) presents similar amplitudes of both exponential terms $\left(\mathrm{A}_{1} \approx \mathrm{A}_{2}\right)$. Both terms show comparable values during the initial part of the curve ( $\sim 6 \mathrm{~s}$ according to $\left.\tau_{1}\right)$, whereas the convection term clearly prevails for the remainder cooling process $\left(\tau_{2} \sim 3 \tau_{1}\right)$. The higher weigh of convention term in the cooling process for the coated structure is probably related to the lower emissivity of $\mathrm{Cu}$ and the higher density $(\rho)$ of the coated structure $\left(0.42\right.$ versus $\left.0.03 \mathrm{~g} \cdot \mathrm{cm}^{-3}\right)$, as the time constant 
for convective cooling depends directly on density, $\tau=\rho c_{p} / h$, being $h$ the heat transfer coefficient and $c_{p}$ the specific heat. ${ }^{1}$

Table S1. Parameter fit to Eq. 1 for the recorded cooling curves of the structures (Fig. 7a of the paper). $\mathrm{R}^{2}$ is the correlation coefficient.

\begin{tabular}{lll}
\hline & rGO & rGO/Cu \\
\hline $\mathrm{T}_{0}\left({ }^{\circ} \mathrm{C}\right)$ & $29.6 \pm 0.2$ & $31.6 \pm 0.1$ \\
$\mathrm{~A}_{1}\left({ }^{\circ} \mathrm{C}\right)$ & $183 \pm 4$ & $135 \pm 3$ \\
$\tau_{1}(\mathrm{~s})$ & $2.74 \pm 0.05$ & $6.0 \pm 0.1$ \\
$\mathrm{~A}_{2}\left({ }^{\circ} \mathrm{C}\right)$ & $120 \pm 4$ & $139 \pm 3$ \\
$\tau_{2}(\mathrm{~s})$ & $0.56 \pm 0.03$ & $16.5 \pm 0.3$ \\
$\mathrm{R}^{2}$ & 0.999 & 0.999 \\
\hline
\end{tabular}

\section{References}

(1) Vollmer, M. Newton's Law of Cooling Revisited. Eur. J. Phys. 2009, 30, 10631084. https://doi.org/10.1088/0143-0807/30/5/014.

(2) Gómez-Gómez, A.; Moyano, J. J.; Román-Manso, B.; Belmonte, M.; Miranzo, P.; Osendi, M. I.; Highly-Porous Hierarchical SiC Structures Obtained by Filament Printing and Partial Sintering. J. Eur. Ceram. Soc. 2019, 39, 688-695. https://doi.org/10.1016/j.jeurceramsoc.2018.12.034 